\title{
Representação da masculinidade de homens acadêmicos e sua implicação para o campo da saúde
}

RESUMO | Objetivo: conhecer a representação da masculinidade dos homens acadêmicos da Universidade Federal Fluminense e analisar suas implicações para o campo da saúde. Método: trata-se de um estudo descritivo, exploratório, de natureza qualitativa que teve como referencial metodológico a hermenêutica-dialética. Foi submetido ao Comitê de Ética do Hospital Universitário Antônio Pedro sob o CAAE 0264.0.258.000-10. Os participantes da pesquisa foram quinze acadêmicos do gênero masculino, de diferentes cursos de graduação da universidade. Utilizou-se o questionário de dados sociodemográficos e um instrumento de entrevista semiestruturada. Resultados: os depoimentos mostraram a importância de conhecer a representação que cada indivíduo possui acerca de sua masculinidade, para que melhor se compreenda o homem e suas expectativas. Conclusão: o reduzido envolvimento dos acadêmicos com os cuidados em saúde decorre em função dos modelos de masculinidade estabelecidos ao longo da vida do homem. Palavras-chaves: Masculinidade; Gênero; Saúde do homem; Cuidado.

ABSTRACT | Objective: to know the representation of masculinity of academic men at Universidade Federal Fluminense and analyze its implications for the health field. Method: this is a descriptive, exploratory, qualitative study that used the hermeneutic-dialectic methodological framework. Submitted to the Ethics Committee of Hospital Universitário Antônio Pedro under CAAE 0264.0.258.00010. The participants were fifteen male academics, from different undergraduate courses in university. The socio-demographic data questionnaire and a semi-structured interview instrument were used. Results: the testimonies showed the importance of knowing the representation that each individual has about his masculinity, in order to better understand the man and his expectations. Conclusion: the reduced involvement of academics in health care is due to the masculinity models established throughout the life of men.

Keywords: Masculinity; Gender; Men's health; Care.

RESUMEN | Objetivo: conocer la representación de la masculinidad de los académicos en la Universidade Federal Fluminense y analizar sus implicaciones para el campo de la salud. Método: se trata de un estudio descriptivo, exploratorio y cualitativo que utilizó el marco metodológico hermenéutico-dialéctico. Fue presentado al Comité de Ética del Hospital Universitario Antonio Pedro bajo CAAE 0264.0.258.000-10. Los participantes de la investigación fueron quince académicos masculinos, de diferentes cursos de pregrado en la universidad. Se utilizó el cuestionario de datos sociodemográficos y un instrumento de entrevista semiestructurada. Resultados: los testimonios mostraron la importancia de conocer la representación que cada indivíduo tiene sobre su masculinidad, para comprender mejor al hombre y sus expectativas. Conclusión: la menor participación de los académicos en la atención médica se debe a los modelos de masculinidad establecidos a lo largo de la vida de los hombres.

Palabras claves: Masculinidad; Género; Salud masculina; Cuidado.

\section{Felipe dos Santos Glutter}

Enfermeiro. Graduação em Enfermagem, Universidade Federal Fluminense, Rio de Janeiro, Niterói. Especialização em Enfermagem Neonatal pelo Instituto Fernandes Figueira - IFF, FIOCRUZ. ORCID: 0000-0002-9276-7721

\section{Cristina Portela da Mota}

Enfermeira. Doutorado em saúde pública pela Escola Nacional Sérgio Arouca da FIOCRUZ. Professora ajunta da Universidade Federal Fluminense.

ORCID: 0000-0001-7496-3385

\section{Jorge Luiz da Silva Lima}

Enfermeiro. Doutorado em saúde pública pela Escola Nacional Sérgio Arouca da FIOCRUZ. Professor da Universidade Federal Fluminense, departamento materno-infantil e psiquiatria. ORCID: 0000-0002-2370-6343

Recebido em: 30/07/2020

Aprovado em: 13/09/2020

\section{Cláudia Maria Messias}

Enfermeira. Pós doutorado na Escola de Enfermagem Aurora de Afonso Costa da Universidade Federal Fluminense. Professora adjunta da Universidade Federal Fluminense, departamento materno-infantil e psiquiatria.

ORCID: 0000-0002-1323-0214

\section{Ricardo José de Oliveira Mouta}

Enfermeiro. Doutor pela Universidade do Estado do Rio de Janeiro (UERJ) na área de Saúde da Mulher. Professor Adjunto do Departamento Materno Infantil da Faculdade de Enfermagem da UERJ

ORCID: 0000-0002-1284-971X

\section{Larissa Murta Abreu}

Acadêmica de enfermagem na Escola de Enfermagem Aurora de Afonso Costa da Universidade Federal Fluminense.

ORCID: 0000-0002-7119-4370
INTRODUÇÃO

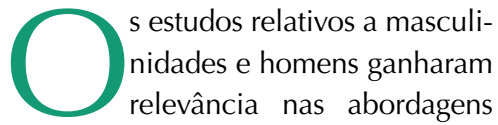
de gênero nas últimas duas décadas no país, em que a relação homem e saúde é objeto de atenção nos meios acadêmicos e também no contexto dos serviços de saúde, especialmente nas análises da sexualidade humana e saúde reprodutiva ${ }^{(1)}$.

As pesquisas de gênero em saúde constituem um complexo e relacional campo com grandes possibilidades de desenvolvimento. Complexo, pois engloba temas (de saúde, adoecimento e cuidado) que tanto podem ser abordados no interior dos campos da saúde e das ciências humanas e sociais, independentemente, como de uma pers- 
pectiva de aproximação e colaboração entre eles ${ }^{(2)}$.

Ao longo da história, a masculinidade se apresenta de diferentes formas dentro da conjuntura social e cultural. Tendo o homem como um "ser social", não se pode negar que apesar dessa "liberdade" ainda existem determinados padrões sociais a serem adotados. A pressão social envolve desde relações com pessoas próximas, como família e amigos, até relações de menor intimidade. O "roteiro" social desenvolvido para homens exerce pressão, mesmo que, inconsciente sobre pensamentos e atitudes onde a masculinidade se encontra quase sempre atrelada a essa figuração ${ }^{(3-4)}$.

No âmbito da saúde coletiva, a preocupação com a temática da saúde masculina ainda é recente e incipiente, porém em constante produção. Diversos estudos apontam para as implicações dos sentidos atribuídos ao "ser homem" nas condições de saúde, bem estar e qualidade de vida da população masculina brasileira ${ }^{(5)}$. Apesar das recentes iniciativas governamentais, os homens ainda se encontram distantes dos serviços de saúde e das práticas de cuidado, sobretudo aqueles voltados para a promoção da saúde e prevenção de doenças, resultando assim em maiores taxas de adoecimento, internações hospitalares e morte entre essa população ${ }^{(6-7)}$.

Uma das dificuldades no tratamento à saúde dos homens é a questão de gênero, enraizada na sociedade, acerca da invulnerabilidade masculina. Segundo Ministério da Saúde ${ }^{(7)}$, os homens têm dificuldade em reconhecer suas necessidades, cultivando o pensamento mágico que rejeita a possibilidade de adoecer.

Além disto, o processo de adoecer dos homens está ligado a representação sobre a masculinidade que compromete o acesso à atenção primária, bem como repercutem de modo crítico na vulnerabilidade deste grupo populacional ${ }^{(7)}$.

Para o desenvolvimento deste estudo traçou-se como objetivo conhecer a representação da masculinidade dos homens acadêmicos da Universidade Federal Fluminense. Buscou-se analisar as implicações da representação da masculinidade para o campo da saúde.

\section{C6 \\ Uma das dificuldades no tratamento à saúde dos homens é a questão de gênero, enraizada na sociedade, acerca da invulnerabilidade masculina. Segundo Ministério da Saúde, os homens têm dificuldade em reconhecer suas necessidades, cultivando o pensamento mágico que rejeita a possibilidade de adoecer.}

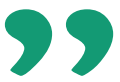

MÉTODO

Trata-se de um estudo descritivo, exploratório de natureza qualitativa. A abordagem qualitativa, em ciências sociais, pode ser ancorada em diferentes referenciais teórico-metodológicos. Optou-se pela perspectiva hermenêutico-dialética.

A abordagem hermenêutica, do ponto de vista metodológico, desenvolve-se nos seguintes parâmetros: busca diferenças e semelhanças entre o contexto dos autores e o contexto do investigador; explora as definições de situação do ator, supõe o compartilhamento entre o mundo observado e os sujeitos, com o mundo da vida do investigador; busca entender os fatos, os relatos e as observações e apoia essa reflexão sobre o contexto histórico; julga e toma decisão sobre o que ouve, observa e compartilha; e produz um relato dos fatos em que os diferentes atores se sintam contemplados.

A abordagem dialética busca nos fatos, na linguagem, nos símbolos e na cultura, os núcleos obscuros e contraditórios para realizar uma crítica sobre eles. O pensamento dialético precisa criar instrumentos de crítica e de apreensão das contradições da linguagem, compreender que a análise dos significados deve ser colocada no chão das práticas sociais, valorizar os processos na dinâmica das contradições, no interior das quais a própria oposição entre o avaliador e avaliado se colocam, e ressaltar o condicionamento histórico das falas, relações e ações ${ }^{(8)}$.

Para a coleta de dados, no primeiro momento, utilizou-se um questionário com quatorze perguntas, categorizadas em perguntas fechadas que dizem respeito à produção de dados sociodemográficos objetivos que caracterizam os homens acadêmicos participantes do estudo. No segundo momento da coleta dos dados, realizou-se uma entrevista semiestruturada, com perguntas abertas e de ordem subjetiva.

Os participantes da pesquisa foram quinze homens acadêmicos pertencentes aos diversos cursos de graduação da Universidade Federal Fluminense, de diferentes faixas etárias, etnias e classes sociais, porém todos do gênero masculino.

$\mathrm{O}$ primeiro contato com os participantes ocorreu após estabelecer uma relação de confiabilidade, respeito e segurança com esses acadêmicos, onde cada um foi convidado, por meio de carta-convite para participar da pesquisa. A 
correspondência continha uma descrição sucinta sobre os objetivos e a proposta do estudo, questões referentes à identificação dos pesquisadores e sua disponibilidade para participar da pesquisa. A fim de dar cumprimento às questões éticas em pesquisa, o estudo foi submetido ao Comitê de Ética do Hospital Universitário Antônio Pedro sob o CAAE 0264.0.258.000-10.

A partir dos dados coletados foram formuladas categorias nas quais foram agrupados elementos, ideias, expressões e palavras que se repetem ou são frequentes, para estabelecer classificações. A categorização dos dados significa apontar categorias nas quais se encaixam as expressões emitidas sobre um tema. $\mathrm{O}$ assunto, assim, é organizado de acordo com as palavras que costumam ser frequentes e que podem fornecer explicação consensual ${ }^{(9)}$.

\section{RESULTADOS}

A escolha dos entrevistados deu-se de forma a buscar uma grande diversidade dos Cursos de Graduação da UFF, respeitando a vontade deles em quererem participar do estudo e para facilitar a compreensão do leitor, foram colhidos os dados sociodemográficos que dizem respeito à idade, estado civil, curso de graduação, religião, moradia, hábitos de vida e cuidados com a saúde dos acadêmicos do gênero masculino.

Os homens acadêmicos da Universidade Federal Fluminense estão na faixa etária de 18 a 23 anos de idade, representando $27 \%{ }^{(4)}$ e todos se declararam solteiros. Desta forma, eles estão na fase da juventude e segundo D'Andrea ${ }^{(10)}$, vivenciar a juventude é uma situação difícil, pois nesta fase da vida, o indivíduo se separa emocionalmente dos pais e desenvolve uma identidade pessoal e sexual.

$\mathrm{Na}$ análise da distribuição dos cursos de graduação a qual pertencem os quinze homens acadêmicos da Universidade Federal Fluminense, $20 \%{ }^{(3)}$ eram do curso de biblioteconomia; $13 \%{ }^{(2)}$ eram do cur- so de letras, produção cultural, economia e de jornalismo. Um total de $7 \%{ }^{(1)}$ eram do curso de serviço social, medicina e enfermagem. Procurou-se, neste estudo, entrevistar uma ampla diversidade de cursos superiores, a fim de obter uma maior heterogeneidade de ideias e opiniões centrais sobre a representação da masculinidade e suas implicações para o campo da saúde.

Em relação ao quesito cor/raça, percebeu-se que $67 \%{ }^{(10)}$ declararam ser brancos; $13 \%{ }^{(2)}$ pardos e $7 \%{ }^{(1)}$ negro e mulato ou ignora. Muitos jovens não sabiam em qual classificação se enquadrar, porém, houve uma prevalência na cor "branco", apesar de muitos marcarem esta opção usando a justificativa de que no Brasil não existem brancos.

Na questão religiosa, 33\% ${ }^{(5)}$ disseram acreditar em Deus, porém não tem religião; $20 \%{ }^{(3)}$ se disseram ser protestante ou não acreditar em Deus e $7 \%{ }^{(1)}$ disseram ser espírita ou católico não praticante. Cada religião tem suas diferenças quanto a alguns aspectos, porém, a grande maioria se assemelha em acreditar em algo ou alguém do plano superior e na vida após a morte.

Quanto à frequência em que os homens acadêmicos da Universidade Federal Fluminense procuram atendimento de saúde, 53\% ${ }^{(8)}$ afirmaram procurar atendimento de saúde somente quando sentem algum tipo de dor; $20 \%{ }^{(3)}$ procuram periodicamente e $7 \%{ }^{(1)}$ procuram sempre que possível. Luck ${ }^{(11)}$ e Courtenay ${ }^{(12)}$ em seus estudos constataram que os homens, em geral, padecem de condições severas e crônicas de saúde do que as mulheres e também, morrem mais do que elas pelas principais causas de morte.

Em relação à última vez que os entrevistados receberam assistência de saúde, o estudo apontou que $53 \%{ }^{(8)}$ receberam essa assistência entre 1 mês e menos de 1 ano; $20 \%{ }^{(3)}$ receberam nos últimos trinta dias ou receberam entre 1 ano e menos de 2 anos e $7 \%{ }^{(1)}$ recebeu a cinco ou mais anos atrás. De acordo com o departamento de ações estratégicas e progra- mas do Ministério da Saúde, a diferença no cuidado com a saúde é atribuída a fatores culturais. Enquanto, a menina é estimulada a procurar o ginecologista desde o início da menstruação e a fazer exames preventivos a partir da primeira relação sexual, o rapaz só vai ao médico quando está doente ${ }^{(7)}$.

Quando questionados sobre os locais de atendimento de saúde $46 \%{ }^{\text {(7) }}$ são atendidos em consultório médico particular; $27 \%{ }^{(4)}$ são atendidos em posto ou centro de saúde; $20 \%{ }^{\left({ }^{3)}\right.}$ em ambulatório de hospital e $7 \%{ }^{(1)}$ em farmácia. Atualmente, a auto medicalização vem sendo fortemente discutida em nossa sociedade, em virtude do incessante aumento de consumo indevido de fármaco. Segundo Slater $^{(13)}$ a cultura do consumo, estabelecida no século XIX, se fundamenta sobre o consumo de mercadorias onde o mercado é mediador nas relações sociais. Desta forma, tal acontecimento promove a diversificação dos fármacos, gerando a necessidade de criar demanda de consumo o que, consequentemente, coloca a propaganda como veículo fundamental para divulgação de um novo significado da medicação.

Ao examinar os discursos dos acadêmicos e, após leitura das entrevistas, foi desenvolvida uma categoria temática discutida no tópico abaixo.

\section{DISCUSSÃO}

Ser e tornar-se homem na sociedade brasileira: refletindo sobre masculinidades

Quando se questionou aos acadêmicos da Universidade Federal Fluminense, como eles representam a masculinidade e quais os atributos que a define, eles determinaram que a masculinidade é uma construção sociocultural e histórica, rejeitando-se que a biologia por si explique as diferenças entre os sexos:

É um estereótipo...um rótulo da sociedade, uma rotulação que se modifica ao longo dos tempos. (Entrevistado 1)

Até os dias atuais, a masculinida- 
de é um estereótipo, pois para a sociedade o homem tem que ser forte, tem que ser responsável e tem que impor respeito. (Entrevistado 2)

A masculinidade está presente na maneira como nos vestimos e na manifestação de nossas atitudes diante das situações e problemas que surgem na vida. (Entrevistado 13)

Keijer $^{(14)}$ argumenta que podemos compreender as marcas identitárias da masculinidade, situadas no âmbito das relações de gênero, como um conjunto de atributos, valores, funções e condutas que se espera que o homem tenha numa determinada cultura.

Na nossa sociedade existe um papel para o homem e outro para a mulher. Ao homem coube o espaço fora de casa, de caçar, de construir, de produzir. Já à muIher o espaço do lar, de nutrir de comida e afeto, de educar, de se responsabilizar pelo outro. Enfim, por muito tempo, ao homem foi reservado o espaço do prover e à mulher coube o espaço do cuidar. Dentre os atributos que definem a masculinidade, destaca-se a fala de dois homens acadêmicos da Universidade Federal Fluminense que tem a heterossexualidade como característica principal de masculinidade:

$\mathrm{Na}$ minha opinião, o que define masculinidade seria o fato de você nascer homem, com a compreensão física de homem e, claro, no meu caso permanecer, assim, na heterossexualidade. (Entrevistado 15)

Acho que a masculinidade é uma questão de você se sentir atraído por uma mulher. (Entrevistado 14)

As falas dos participantes encontram-se em consonância com a produção de variados pesquisadores que descrevem as masculinidades e suas diferentes formas. Segundo Welzer-Lang ${ }^{(15)}$ assimilando a sexualidade masculina e sua cota de jo- gos, desejos e prazeres, o paradigma heterossexual se impôs como linha de conduta para os homens.

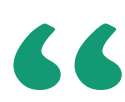

descritas são muito marcadas e presentes na vida da grande maioria dos homens da sociedade brasileira. Gomes ${ }^{(16)}$ refere que o modelo de masculinidade hegemônica, destacam-se como eixos estruturantes a heterossexualidade e a dominação.

Em outro artigo, o modelo hegemônico de masculinidade também é citado por Garcia ${ }^{(17)}$ que menciona que os valores hegemônicos das masculinidades são descritos por seus atributos, tais como: homem provedor, viril, agressivo, conquistador, com necessidade de demonstrar sua força, competitividade e heterossexualidade.

O participante 11, um universitário do curso de graduação em letras, com 28 anos de idade chama a atenção, ao mencionar como principal atributo da masculinidade a honra, como demonstrado na frase:

Acho que o maior atributo da masculinidade é a força, é a honra (...) Eu estou sempre buscando ser uma pessoa honrada, buscando sempre uma força. (Entrevistado 11)

Autores explicitam que a construção simbólica da masculinidade, articula-se em torno do desafio da honra de disputa entre homens e do controle das mulheres. Neste sentido, pode-se constatar que, apesar de fazerem parte de uma geração jovem, de terem uma formação mais elevada e reflexiva em relação a grande parte da população brasileira, as questões relacionadas à masculinidade estão enraizadas e são reproduzidas de geração a geração.

Muitas pessoas têm a ideia pré-concebida de que a humanidade toda é heterossexual e que uma minoria de indivíduos se encontra "viciada" num comportamento homossexual.

Para Bortolini. ${ }^{(18)}$ quando o assunto é

Desta forma, nas falas desses homens acadêmicos, remete ao que os estudiosos chamam de um modelo hegemônico de masculinidade, onde as características homossexualidade ou transexualidade, o que não falta são opiniões. Algumas baseadas em conceitos, ideias e crenças e outras são construídas em cima apenas 
do senso comum e mesmo do completo desconhecimento. Se olharmos à nossa volta, perceberemos que vivemos em uma sociedade com valores patriarcais, na qual impera entre os diferentes estereótipos que cercam os homens homossexuais, serem pessoas sensíveis e afeminadas, que faz pegação no banheiro e/ ou que se agarra em lugares públicos no meio da noite.

Há espaços e/ou situações onde as masculinidades e feminilidades entram em maior evidência. Nestes espaços, a prevalência pode se dá até mesmo de forma não planejada, mas baseada em uma conjuntura social de diferenciação de gênero. Considerando-se que o gênero é uma categoria fundamental na vivência das práticas corporais no esporte e no lazer, e que a dimensão de gênero, também, está presente no amplo âmbito das relações humanas nas práticas esportivas e culturais. De acordo com os entrevistados, alguns espaços e/ou situações podem ser considerar características exclusivamente masculinas:

Bares e ambientes ligados ao futebol e a luta livre. (Entrevistado 7) ou estádios de futebol e boteco. (Entrevistado 15)

A existência de espaços onde a masculinidade se apresenta de forma mais expressiva, não é algo incomum. Tais espaços e/ou situações são importantes no sentido de reafirmarem as masculinidades. Segundo Paim e Strez ${ }^{(19)}$, no momento em que uma pessoa participa de uma torcida organizada, ela está sendo constituída de situações de expansão de várias emoções, muitas vezes, reprimidas pelo meio social do cotidiano. Desta forma, é diante da torcida que essa pessoa demonstra sua identidade e começa a manifestar e agir de maneira que não faria isoladamente, colocando para fora todo sentimento de impotência e frustração pessoal, que foram diluídas no coletivo das arquibancadas.

Portanto, Gomes ${ }^{(16)}$ refere que essa aprendizagem costuma ocorrer em lugares monossexuados de homossociabilidade - espaços de que só homens participam - mediante o convencimento de que, para ser homem, deve-se combater o que poderia ser associado à mulher. Entretanto, para alguns entrevistados esses espaços e/ou situações não são de exclusividade masculina, pois eles valorizam a equidade de gênero nos mais variados ambientes públicos.

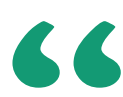

Há espaços e/ ou situações onde as masculinidades e feminilidades entram em maior evidência. Nestes espaços, a prevalência pode se dá até mesmo de forma não planejada, mas baseada em uma conjuntura social de diferenciação de gênero.

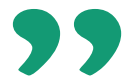

Acredito que não tenha ambientes exclusivamente masculinos. Acho que os ambientes públicos são para os dois gêneros. (Entrevistado 12)
Não tem um espaço específico. Acho que essa questão de você delimitar espaços específicos é muito segregador. (Entrevistado 4)

Há ainda entrevistados que direcionaram os espaços e/ou situações exclusivamente masculinas à profissão, como sendo mais prevalentes para homens e para mulheres, evidenciando uma forma de autoafirmação da masculinidade, e a negação do feminino. Gomes (2008, p. 73) ${ }^{(16)}$ observa que a percepção do masculino como oposto ao que é visto como feminino ainda está muito incorporada ao nosso cotidiano. Nos depoimentos dos entrevistados isto pode ser notado.

Os pais são os primeiros educadores com os quais as crianças têm contato, não há como negar que inúmeras informações e códigos sociais serão transmitidos e absorvidos pelos filhos, ainda que estes possam mudar ao longo dos anos acompanhados das experiências individuais. Humphreys ${ }^{(20)}$ refere que a família é o primeiro núcleo de socialização dos indivíduos. Ela é responsável pela transmissão dos valores, usos e costumes que irão formar a personalidade e a bagagem emocional do ser humano.

Baseados nessas experiências pode-se indagar aos entrevistados se a representação da masculinidade sofre mudanças ao longo dos tempos e pode-se perceber nos relatos a seguir, um grande destaque nos aspectos históricos e temporais:

A masculinidade com o passar do tempo vem sofrendo mudanças. De acordo, com as influências que a pessoa tem ao longo da vida, com as experiências e com o repertório que a pessoa tem ao longo da vida. (Entrevistado 9) A masculinidade muda, às vezes, de médio a longo prazo. Mas isso se dá a todo tempo. (Entrevistado 7)

Para Gomes ${ }^{(16)}$ existe a concepção segundo a qual homens e mulheres são transhistóricos, eternos e as essências 
imutáveis vem sendo amplamente criticada. Ainda acerca da evolução das representações das masculinidades, Garcia ressalta (2006, p.37) (17) a hegemonia é vista como historicamente mutável.

$\mathrm{Na}$ concepção de alguns pesquisadores as diferentes formas de expressar a masculinidade sofrem mudanças ao longo da história das civilizações. Em cada época histórica, são construídos valores e expectativas de modelos aos quais os sexos devem se ajustar para lograrem minimamente uma respeitabilidade social.

O que se compreende nos discursos dos acadêmicos da Universidade Federal Fluminense é que a representação da masculinidade sofreu mudanças, ainda que, sejam elas classificadas apenas como uma forma de amadurecimento e este só se fez de fato pelas vivências adquiridas no percurso da vida. Levando em consideração que as masculinidades são construídas em um contexto histórico, social e cultural. Neste contexto, foi pedido aos entrevistados que apontassem algumas dificuldades e facilidades, nos dias atuais, em "ser homem" e em "ser mulher" em nossa sociedade.

Como facilidades, os argumentos que se destacaram foram a condição de liberdade e as relações de disputa de emprego entre os sexos, na qual o homem seria favorecido na maioria das vezes, como se evidencia nos seguintes depoimentos:

Facilidade de ser homem na sociedade...Assim, porque o homem tem certas liberdades, essa é a facilidade. (Entrevistado 4)

Apesar da redução da desigualdade de gênero, inclusive com a promulgação da Lei Federal n. 9.799, de 26 de maio de 1999, que trata singularmente sobre o acesso da mulher no mercado de trabaIho e, de programas próprios do governo federal, é fato que as mulheres encontram dificuldades de inserção no mercado de trabalho e, quando inseridas nesse contexto, recebem menos do que os homens e ocupando cargos hierarquicamente inferiores ${ }^{(21)}$.

A separação das carreiras reflete, em larga medida, a própria divisão sexual do trabalho, traduzindo-se em "carreiras femininas" mais vinculadas às áreas sociais, portanto de "cuidado" e as "carreiras masculinas" conhecidas como ciências exatas, mais técnicas. A essa separação corresponde uma divisão em termos de hierarquia e reconhecimento social e salarial. Enquanto as áreas ditas "femininas" acabam constituindo-se nas carreiras menos valorizadas socialmente, aquelas ocupadas em sua maioria por homens revelam-se espaços com maior remuneração e prestígio social. Já argumento de liberdade mencionada pode ser lida como um machismo velado, onde ao homem é permitido um comportamento "transgressor" sem maiores julgamentos e às mulheres cabe a guarda da ética, da moral e do exemplo a ser seguido.

Muraro e Boff(22), apresentam que o processo de individualização à integração dinâmica e sempre difícil do masculino e do feminino [...] Esboça-se por todas as partes um novo tipo de manifestação do feminino e do masculino em termos de parcerias, de colaboração e de solidariedade, nas quais homens e mulheres se acolhem nas suas diferenças no horizonte de uma profunda igualdade pessoal, de origem e de destino, de tarefa e de compromisso na construção de mais benevolência para com a vida e a Terra e de formas sociais mais participativas e democráticas entre os gêneros. Como dificuldades, encontramos o peso das responsabilidades e dos estereótipos na masculinidade hegemônica impostos pela nossa sociedade, como se apresenta nos discursos que se seguem:

Exatamente esse estereótipo. Você tem que se encaixar nele, senão você tem algum problema. (Entrevistado 2)

Uma dificuldade de você em determinados setores, você é obrigado a ter um tipo de postura que talvez você não queira. (Entrevistado 6)

Discorrendo acerca das dificuldades de "ser homem", um ponto que nos chama atenção está relacionada com o fato de homens terem interesse pelo campo das artes, conforme pode-se constatar no trecho abaixo:

Eu acho que as pessoas que são ligadas em artes, sempre enfrentam uma dificuldade na parte de se expressar, sempre são taxadas como afeminadas. (Entrevistado 14)

Nestas falas ficam evidentes que os tabus, mitos e estigmas que envolvem a cultura de uma sociedade deturpam o campo de conhecimento na qual as artes visuais, plásticas e cênicas estão inseridas. Simioni ${ }^{(23)}$ salienta que a história da arte é tomada como uma prática discursiva perpassada pelas dinâmicas de gênero, prática essa que se cristaliza na maneira como são construídas as suas categorias valorativas e as hierarquias que definem os próprios objetos sobre as quais se debruça enquanto disciplina. Esse discurso pedagogizado sobre arte define a criatividade feminina como algo a ser controlado por receitas e prescrições de "como fazer", escapando de qualquer nível de excelência, ou mesmo de qualquer semelhança e visibilidade da chamada "grande arte" (24).

\section{CONCLUSÃO}

A masculinidade é estabelecida ao longo da vida do homem. Estando em sociedade, as questões de gênero envolvidas na organização das relações sociais entre indivíduos do mesmo sexo ou sexo oposto, mantém a conexão com toda a estrutura física, emocional e psíquica de cada homem.

As diferentes masculinidades se dão numa construção histórica, neste sentido, ela evolui e toma diferentes formas e significados de acordo com o tempo históri- 
co, geração, etnia e grupo social.

Hoje, a masculinidade assume uma forma plural, respeitando as diferenças entre os homens, ainda que, de uma mesma geração, etnia ou classe social. Apesar dessa tendência à diversificação, muitos, ainda não enxergam dessa maneira, considerando-se excluídos de um modelo hegemônico, caso haja qualquer fuga ou negação ao que é tido como "normal" ou minimamente comum.

No que se expressa essa masculinidade moldada segundo uma conformidade social, há que se aprender o que é previamente proposto e aceito pela sociedade, criando a existência de espaços onde a representação da masculinidade, torna-se evidente, mesmo que alguns desses ambientes também sejam frequentados por mulheres. Esta hegemonia de um estereótipo de masculinidade gera insegurança e insatisfação naqueles que procuram ser da maneira que determinaram para si, pois o julgamento que a sociedade impõe não se deixa passar despercebido.

Tendo uma conjuntura social como base na evolução humana e na representação das masculinidades, a família aparece como primeira rede social onde esse indivíduo se encontra inserido, podendo, esta ensinar-Ihe valores. E apenas apontar o caminho mais adequado para o homem melhor viver a sua masculinidade.

É complexo exercer uma masculinidade numa sociedade que ao mesmo tempo que cobra muitas responsabilidades de um homem e oferece regalias. O meio termo é difícil de ser achado, ainda que, se viva cada um uma masculinidade diferenciada, não se pode negar abstrair uma sociedade que observa e avalia a todo momento seus pertencentes.

Trazendo à luz o campo da saúde, este homem que possui sua masculinidade socialmente construída, é atribuído muitos encargos que despendem um longo tempo livre e de seu vigor físico. Desta forma, questões relativas à saúde são tratadas em um plano inferior, sendo lembradas, na maior parte, somente em casos de dor aguda e/ou crônica.

Criar espaços que tenham uma maior identificação com o público masculino e também, adentrar nos espaços convencionalmente masculinos é fundamental para que se possa promover à saúde, sendo esta não apenas

\section{Referências}

1. Machin R, Couto MT, Silva GSiNd, Schraiber LB Gomes R, Figueiredo WdS, Valença OA, Pinheiro TF. Concepções de gênero, masculinidade e cuidados em saúde: estudo com profissionais de saúde da atenção primária. Ciência \& Saúde Coletiva [Internet], 2011 [acesso em 29 jul 2020] vol.16, n.11, pp.4503-4512. Disponivel em: https://www.scielo.br/scielo.php?pi$\mathrm{d}=\$ 141381232011001200023 \&$ script=sci_abstract\&tlng=pt.

2. Couto MT, Dantas SMV. Gênero, masculinidades e saúde em revista: a produção da área na revista Saúde e Sociedade. Saúde e Sociedade [Internet]. 2016, v.25, n.4, [acesso em 29 jul 2020], p.857-868. Disponível em: https:/l www.scielo.br/scielo.php?pid=S010412902016000400857\&script=sci_abstract\&tlng=pt.

3. Garcia S. Homens na intimidade. Masculinidades Contemporâneas. Holos, 2006. $155 \mathrm{p}$.

4. Gagnon JH. Uma interpretação do desejo: ensaios sobre o estudo da sexualidade. Garamond, 2006. 456 p.

5. Gomes R. Sexualidade masculina, gênero e saúde. Editora Fiocruz, 2008. $183 \mathrm{p}$.

6. Figueiredo WS. Assistência à saúde dos homens: um desafio para os serviços de atenção primária. Ciência \& Saúde Coletiva [Internet], 2005 [acesso em 29 jul 2020] v.10, n.1, p. 105-109. Disponível em: https://www.scielo.br/scielo. php?pid=S141381232005000100017\&script=sci_abstract\&tlng=pt.

7. Brasil. Ministério da Saúde. Política Nacional de Atenção Integral à Saúde do Homem: princípios e diretrizes. Brasília: DF, 2009.

8. Minayo MCdS. O Desafio do Conhecimento: pesquisa qualitativa em Saúde. 5.ed. Hucitec-Abrasco, 2010.

9. Leopardi MT, Beck CLC, Nitschke EA, Gonzales RMB. Metodologia da pesquisa em saúde. Pallotti, 2011, 344p.

10. D'andrea FF. Desenvolvimento da personalidade. Difel Difusão Editorial S.A, 2007. 192 p.

11. Luck M, Bamford, $M$, Williamson P. Men's Health: perspectives, diversity and paradox. Blackwell Sciences, 2010.

12. Courteney WH. Constructions of masculinity and their influence on men's well-being: a theory of gender and health. Social Science \& Medicine. [Internet] 2015 [acesso em 29 jul 2020] 50:1385-40. Disponível em: https://pubmed. ncbi.nlm.nih.gov/10741575/.

13. Slater D. Cultura do Consumo e Modernidade. Nobel, 2012. $216 \mathrm{p}$.
14. Keijer B. Hasta donde el cuerpo aguante: género, cuerpo y salud masculina. In: Cáceres C, Cueto M, Ramos M, Vallens S, editores. La salud como derecho ciudadano: perspectivas y propuestas desde América Latina. Lima: Facultad de Salud Pública y Administración, Universidad Peruana Cayetano Herida. 2013, p. 137-52.

15. Welzer-lang D. A construção do masculino, dominação das mulheres e homofobia, Revista Estudos Feministas [Internet], 2011 [acesso em 29 jul 2020], vol. 9, p. 460-48. Disponível em: https://www.scielo.br/pdf/ref/v9n2/8635.pdf. 16. Gomes R. Sexualidade masculina, gênero e saúde. Editora Fiocruz, 2008. $183 \mathrm{p}$.

17. Garcia S. Homens na intimidade. Masculinidades Contemporâneas. Holos, 2006. $155 \mathrm{p}$.

18. Bortolini A. Diversidade sexual na escola. Rio de Janeiro: Pró-reitora de Extensão/UFRJ, 2008.

19. Paim MCC, Strey MN. Violência no contexto esportivo. Uma questão de gênero? Revista Digital Educación Física y Deportes [Internet], maio 2007 [acesso em 29 jul 2020], v. 12, nº. 108. Disponível em: https://www.efdeportes.com/efd108/violencia-no-contexto-esportivo-uma-questao-de genero. htm\#: : text=0utro\%20tipo\%20comum $\% 20 \mathrm{de} \% 20$ viol\%C3\%AAncia,esportiva $\% 2 \mathrm{C} \% 20$ com $\% 20$ preconceitos $\% 20 \mathrm{e} \% 20$ estere $\%$ C3\%B3tipos.\&tex$\mathrm{t}=\mathrm{A} \% 20 \mathrm{pr} \% \mathrm{C} 3 \% \mathrm{~A} 1 \mathrm{tica} \% 20$ de $\% 20$ esportes $\% 20$ ainda, $\% 2$ C $\% 200 \% 20$ handebol\%2C\%20as\%20lutas.

20. Humphreys T. A família: ame-a e deixe-a. Ground, 2010. 285 p.

21. Brasil, Presidência da República. Lei no 9.799 . Insere na Consolidação das Leis do Trabalho regras sobre o acesso da mulher ao mercado de trabalho e dá outras providências. Brasília, 26 de maio de 1999.

22. Muraro RM, Boff L. Feminino/Masculino: Uma consciência para o encontro das diferenças. Editora Sextante, 2012.

23. Simioni APC. Graz Regina Gomide: Modernism, textile art and gender relations in Brazil. Revista do ieb [Internet], set, 2007 [acesso em 29 jul 2020] n.45, p.87-106. Disponível em: file://C:/Users/Usu\%C3\%A1rio/Downloads/ 34583-Texto\%20do\%20artigo-40535-1-10-20120722.pdf.

24. Gruppelli L. Docência Artista: Arte, Gênero e Ético-Estética Docente Laponte, UNISC, UFRGS [Internet]. 2006 [acesso em 29 jul 2020] no ${ }^{\circ}$. 08. Disponivel em: http://www.anped.org.br/sites/default/files/gt08431 int.pdf. 